\title{
Age Related Anatomical Changes in Articular Cartilage of Femoral Head in Buffalo (Bubalus bubalis)
}

\author{
Ranjith Kumar Sundari ${ }^{1 *}$, Pramod Kumar Damaraju ${ }^{1}$, Purushotham Gudepu ${ }^{2}$, \\ Lakshman Mekala ${ }^{3}$ and E.L. Chandrashekhar ${ }^{4}$ \\ ${ }^{1}$ Department of Veterinary Anatomy. College of Veterinary Science, Rajendranagar, Hyderabad, INDIA \\ ${ }^{2}$ Department of Veterinary Anatomy, College of Veterinary Science, Mamnoor, Warangal, INDIA \\ ${ }^{3}$ Department of Veterinary Pathology, College of Veterinary Science, Rajendranagar, Hyderabad, INDIA \\ ${ }^{4}$ Teaching Veterinary Clinical Complex, College of Veterinary Science, Rajendranagar, Hyderabad, INDIA
}

*Corresponding author: RK Sundari; E-mail:varma.dr@gmail.com

Received: 05 May, 2021

Revised: 26 May, 2021

Accepted: 28 May, 2021

\begin{abstract}
Present study was conducted to study the anatomical features of femoral head AC in twenty four intact hip joints of apparently healthy buffaloes procured from GHMC Abbattoir, Hyderabad. They were divided into four groups viz., Group I (prenatal), Group II (Birth - 3yrs), Group III (3 - 6 yrs) and Group IV (6 yrs and above). Morphological features of AC of femoral head revealed that articular surface was covered by a strip of AC made up of hyaline cartilage adjacent to sub-chondral bone in post natal groups, whereas in prenatal stage entire proximal epiphysis of femoral head was purely hyaline cartilage since AC was not yet differentiated. In post natal groups (II, III and IV) a layer of mature AC covered the hemispherical femoral head which blended peripherally with the epiphyseal cartilage. Thickness of femoral head AC reduced marginally with advancing age in various points of articular surface of femoral head viz., lateral surface, at neck and at midpoint. It was $1.89 \mathrm{~mm}, 1.38 \mathrm{~mm}$ and $1.49 \mathrm{~mm}$ thick in Gr-II which reduced to $1.64 \mathrm{~mm}, 1.37 \mathrm{~mm}$ and $1.36 \mathrm{~mm}$ in Gr-IV respectively. As age advanced, average length and width of femoral head increased fivefold from 2.83 and $2.43 \mathrm{~cm}$ in Gr-I (prenatal) to nearly 10.77 and $9.43 \mathrm{~cm}$ in Gr-IV (postnatal) specimens respectively. AC surface of young specimens was shiny pink in color in fresh state, whereas aged specimens it showed signs of yellowish discoloration and few indentations around the neck.
\end{abstract}

\section{HIGHLIGHTS}

(0 Variation in the articular cartilage morphology with the age in buffaloes

(0 Variation in the thickness of AC femoral head at various points with the age from prenatal to postnatal stages in Buffaloes.

Keywords: Articular cartilage, femoral head, buffalo

Articular cartilage is composed of hyaline cartilage which functions to minimize friction between the articulations of synovial joints and act as a shock absorber of the daily loads applied to the joints: both of these serve to protect the underlying bone (Bauman et al. 2019). Therefore, AC plays an important role in joint diseases especially in osteoarthritis where there are specific changes in it and also its repair and remodelling (Taylor et al., 2011). They cited that investigations into these treatments should consider the tribology (study of friction, wear and lubrication) of $\mathrm{AC}$ wherein simulations using animal joints are a predominate choice. It is proposed that tribology and wear of $\mathrm{AC}$ is directly associated with intrinsic mechanical properties. In the literature reviewed so far, many researchers have studied about different joints of bovines and other animals. Most of their research was oriented towards humans and little work has been done on

How to cite this article: Sundari, R.K., Damaraju, P.K., Gudepu, P., Mekala, L. and Chandrashekhar, E.L. (2021). Age related anatomical changes in articular cartilage of femoral head in buffalo (Bubalus bubalis). J. Anim. Res., 11(3): 415-420.

Source of Support: None; Conflict of Interest: None 
hip joint of animals, especially in buffaloes. Hip joint in large animals like buffaloes is an important joint involved in propulsive action in locomotion and also in weight bearing. Therefore present study on the femoral head AC give an idea about the aging changes in the thickness and appearance of articular cartilage at different points.

\section{MATERIALS AND METHODS}

The present investigation was carried out in the Department of Veterinary Anatomy, College of Veterinary Science, Rajendranagar, Hyderabad. Intact hip joint specimens of twenty four (24) apparently healthy buffaloes irrespective of their breed, sex and nutritional status were procured from GHMC Modern Abbattoir, Chengicherla and local slaughter houses in and around Hyderabad. Collected specimens were divided into two primary groups viz., one Prenatal stage - Group I (as per the formula of Soliman 1975) and three Post natal stages as per their approximate age based on dentition pattern by FAO (1994) such as Group II (neonatal), Group III (young adult) and Group IV (aged). Samples were collected from both hind limbs by cutting at the level of mid points of femur to secure the femoral head. Hip joint specimens of all groups were carefully dissected to study gross anatomical surface features of articular cartilages (AC) of femoral head in all age groups. Immediately various gross morphological features were studied, noted and photographed accordingly. Morpho-metrical details as detailed below were recorded with a thread, scale and digital Vernier caliper's (Mitutoyo) which ever was necessary:

$\square \quad$ The average thickness of AC on the head of femur taken from various points.

$\square \quad$ The average length and width of the articular surface of femoral head.

\section{RESULTS AND DISCUSSION}

In the present study, the articular bony surface of buffalo femoral head was covered by AC in post natal groups. These observations are consistent with the description of articular surfaces and anatomy of hip joint in domestic animals by Getty (1984), Dyce et al. (2010), Konig and Leibich (2012) and Supriya et al. (2014). Round ligament of hip joint noticed from pre to post natal stages of buffalo in this study extended from fovea capitis of femoral head to centre of acetabulum, which was also reported by Supriya et al. (2014) in buffalo calves.

AC of femoral head in prenatal group (Gr-I) was unclear and not yet differentiated at this age which was evident in sagittal sections of entire femoral head. Right from its articular surface to its depth, the tissue was typical hyaline cartilage (Fig. 1).

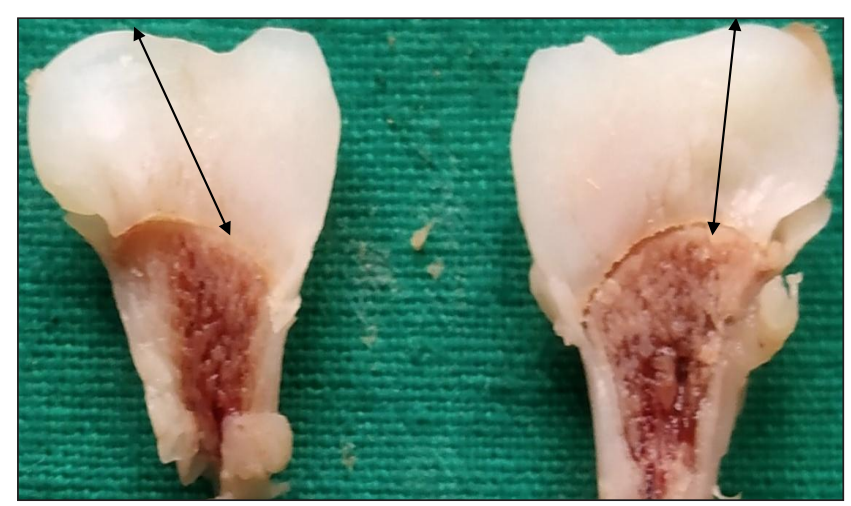

Fig. 1: Photograph of sagittal section of proximal extremity of femoral head in 3 months old buffalo calf (Group - I) showing entire cartilaginous structure (double sided arrow) without any differentiation of $\mathrm{AC}$

Femoral head was hemispherical and merged into cartilaginous part of greater trochanter on the outside presenting a saddle shaped surface which was also reported by Supriya et al. (2014) in buffalo calves who stated that the femoral head was nearly hemispherical with smooth articular saddle shaped surface extending on to the dorsal part of the neck closer to trochanter. Cartilaginous femoral head seen in 3 and 4 month old fetuses in this study is akin to studies of morphogenesis of human femur by Suzuki et al. (2019). They stated that entire proximal epiphysis of femur was cartilaginous with growth plates and cartilage canals in early weeks ( $8-10 \mathrm{wks})$ of development.

A layer of mature AC adapted and covered the hemispherical femoral head entirely in specimens of all three postnatal groups (II, III and IV) in this study. It was clearly appreciable and was smooth and hard to touch when compared to prenatal specimens. AC was spherical at the tip of proximal extremity of femoral head and it sloped down towards the neck region (Fig. 2). These observations are in concurrence to the description of femoral head AC in various domestic animals by several authors such as Friend (1959) in domestic animals like 
dog, ox and horse; Kobrynczuk (1976) in European bison; Dyce et al. (2010) in domestic animals and Supriya et al. (2014) in buffalo calves. They opined that femoral head AC blended peripherally with epiphyseal cartilage and it covered the surface of the neck, merging into cartilaginous structure of the trochanter on the outside in fetuses and newborns, whereas in adults it covered only the surface of head except for its fovea.

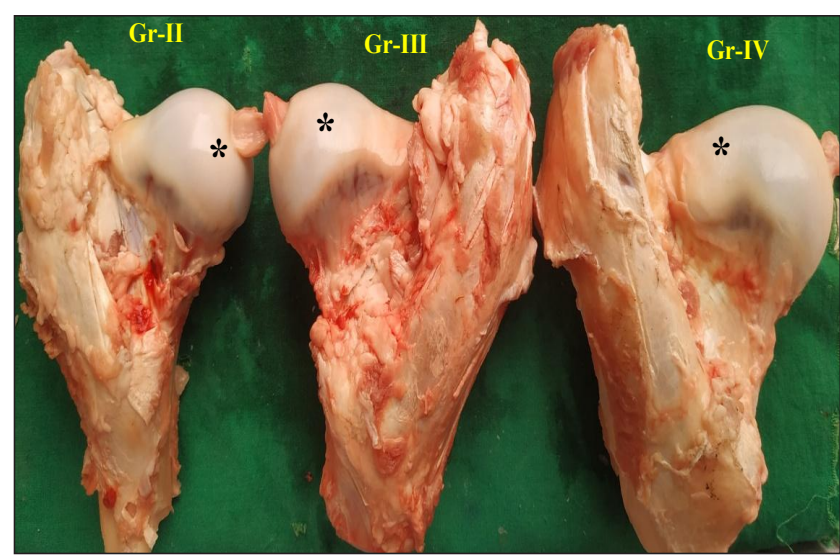

Fig. 2: Photograph showing saddle shaped $A C(*)$ on the femoral head in Groups - II, III and IV buffalo specimens

Slight variation in thickness of femoral head AC observed in post natal groups (II, III and IV) of this study is in agreement with many authors who reported that the AC on femoral head varied in its thickness across various animal species. However, in European Bison Kobrynczuk (1976) stated that $\mathrm{AC}$ had no great variation in its thickness near the margin and at the centre.

With advancing age the average length and width of femoral head increased fivefold from 2.83 and $2.43 \mathrm{~cm}$ in Gr-I (prenatal) to nearly 10.77 and $9.43 \mathrm{~cm}$ in GrIV (postnatal) specimens respectively (Table 1). These observation are akin to the reports of Fermor et al. (2015) who stated bovine femoral head measured $8 \mathrm{~cm}$ from teres ligament to femoral neck. They also reported that porcine femoral head was $4.0 \mathrm{~cm}$ and that of ovine was $2.0 \mathrm{~cm}$ which is lesser than the bovine. They further stated that the bovine AC appeared white, glossy and healthy with exception of ovine species aged more than 4 years which had yellowish appearance in most cases. Similarly in young specimens of groups II and III in this study the articular surface of femoral head was shiny pink in color in fresh state whereas in aged specimens of Gr - IV it showed slight signs of discoloration such as yellowish appearance in spots near fovea capitis along with few indentations around femoral neck which establishes that with advancing age femoral head articular surface changes are possible due to wear and tear in aged bovines (Fig. 3).

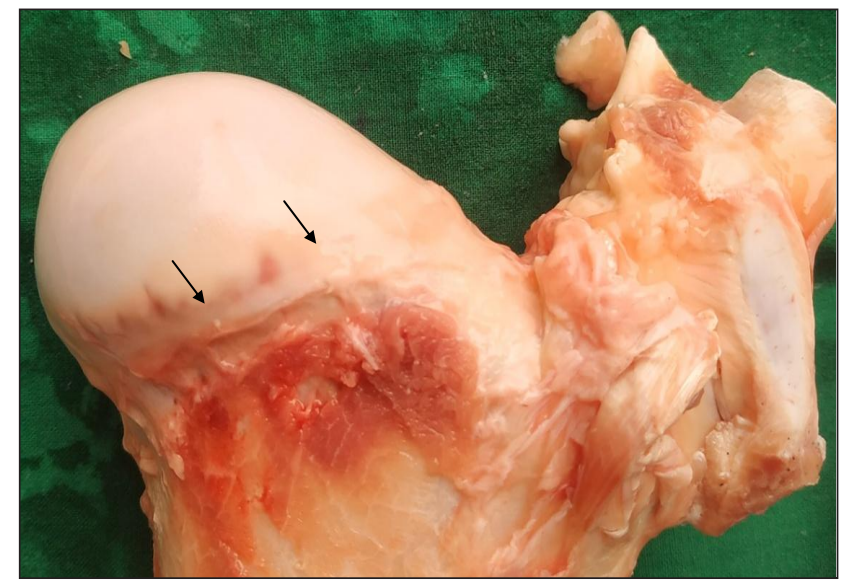

Fig. 3: Photograph of femoral head AC showing indentations (black arrows) at level of neck of femur in Group-IV specimen (aged approximately 8 years)

This study confirms the that femoral head in large ruminants is bulkier part of hip joint, because the latter bears a significant portion of body weight and it helps the animal in its forward propulsive motion. AC covered the entire femoral head going beyond the limit of acetabular rim to support all possible moments of locomotion. These findings are similar to reports of Byrne et al. (2010) who stated that human femoral head was covered approximately 60 to $70 \%$ of the sphere with corresponding $\mathrm{AC}$ beyond the reaches of acetabular brim to accommodate full range of motion.

Variation in thickness of femoral head AC recorded in this study reduced marginally with advancing age in various points of articular surface viz., lateral surface, at neck and at midpoint of femoral head. Average thickness of AC at these points was $1.89 \mathrm{~mm}, 1.38 \mathrm{~mm}$ and $1.49 \mathrm{~mm}$ in Gr-II which reduced to $1.64 \mathrm{~mm}, 1.37 \mathrm{~mm}$ and $1.36 \mathrm{~mm}$ in aged specimens of Gr-IV respectively (Table 2). These findings are akin to reports of Kobrynczuk (1976) who stated that thickness of femoral head AC in European bison showed variation such as it was $4 \mathrm{~mm}$ in youngest specimens at fovea capitis, $5-6 \mathrm{~mm}$ in the periphery and in adults it was 1.0 to $1.5 \mathrm{~mm}$. 
In domestic pig and wild boar Caprinisan (2007) revealed that thickness of $\mathrm{AC}$ of femoral head varied with the area and maximum mechanical stress.

Table 1: Morphometrical measurements of Articular surface area of femoral head

\begin{tabular}{|c|c|c|c|}
\hline \multirow{2}{*}{ Sl. No. } & \multicolumn{3}{|c|}{$\begin{array}{l}\text { Femoral head - articular surface area } \\
\text { (covered by AC) }\end{array}$} \\
\hline & Group & $\begin{array}{l}\text { Length (in } \\
\text { cm) }\end{array}$ & $\begin{array}{l}\text { Width (in } \\
\text { cm) }\end{array}$ \\
\hline 1 & \multirow{6}{*}{$\begin{array}{l}I \\
(n=6)\end{array}$} & 2.5 & 2.3 \\
\hline 2 & & 2.1 & 2.0 \\
\hline 3 & & 2.8 & 2.3 \\
\hline 4 & & 3.0 & 2.5 \\
\hline 5 & & 3.1 & 2.5 \\
\hline 6 & & 3.5 & 3.0 \\
\hline & Average (Gr- I) & $2.83 \mathrm{~cm}$ & $2.43 \mathrm{~cm}$ \\
\hline 7 & \multirow{6}{*}{$\begin{array}{l}\text { II } \\
(n=6)\end{array}$} & 8.0 & 6.9 \\
\hline 8 & & 8.2 & 7.2 \\
\hline 9 & & 7.9 & 7.2 \\
\hline 10 & & 8.4 & 7.6 \\
\hline 11 & & 8.0 & 6.7 \\
\hline \multirow[t]{2}{*}{12} & & 8.8 & 7.6 \\
\hline & Average (Gr- II) & $8.22 \mathrm{~cm}$ & $7.20 \mathrm{~cm}$ \\
\hline 13 & \multirow{6}{*}{$\begin{array}{l}\text { III } \\
(n=6)\end{array}$} & 10.4 & 9.9 \\
\hline 14 & & 9.5 & 8.3 \\
\hline 15 & & 8.9 & 8.2 \\
\hline 16 & & 9.1 & 8.3 \\
\hline 17 & & 10.4 & 9.8 \\
\hline \multirow[t]{2}{*}{18} & & 10.6 & 9.3 \\
\hline & Average (Gr-III) & $9.82 \mathrm{~cm}$ & $8.97 \mathrm{~cm}$ \\
\hline 19 & \multirow{6}{*}{$\begin{array}{l}\text { IV } \\
(n=6)\end{array}$} & 11.0 & 9.9 \\
\hline 20 & & 10.7 & 9.5 \\
\hline 21 & & 11.0 & 9.5 \\
\hline 22 & & 10.6 & 9.2 \\
\hline 23 & & 10.5 & 9.1 \\
\hline 24 & & 10.8 & 9.4 \\
\hline & Average (Gr- IV) & $10.77 \mathrm{~cm}$ & $9.43 \mathrm{~cm}$ \\
\hline
\end{tabular}

However, in human femoral heads Armstrong and Gardner (1977) stated that radiographic studies identified that femoral head AC was thickest at anterior to zenith. They opined that it increased in this zone between the age 20 and 45 years and was not related to femoral head diameter, femur length or body weight. Kurrat and Oberlander (1978) and Sheperd and Seedhom (1999) stated that human femoral head $\mathrm{AC}$ was thickest around axis point of head i.e., ventro-lateral area of head of femur beyond which it decreased concentrically. This feature is similar to the distribution of AC thickness in post natal groups in this study wherein it was slightly higher at lateral surface of femoral head.

Table 2: Thickness of Articular Cartilage (AC) on femoral head surface

\begin{tabular}{|c|c|c|c|c|c|}
\hline \multirow[b]{2}{*}{$\begin{array}{l}\text { S1. } \\
\text { No. }\end{array}$} & \multicolumn{5}{|c|}{ Femoral head - Articular Cartilage thickness (in mm) } \\
\hline & Group & $\begin{array}{l}\text { Pt. } 1 \\
\text { (fovea } \\
\text { capitis) }\end{array}$ & $\begin{array}{l}\text { Pt. } 2 \\
\text { (lateral } \\
\text { surf.) } \\
\end{array}$ & $\begin{array}{l}\text { Pt. } 3 \\
\text { (at neck) }\end{array}$ & $\begin{array}{l}\text { Pt. } 4 \\
\text { (mid point) }\end{array}$ \\
\hline & I & \multicolumn{4}{|l|}{ AC not yet } \\
\hline & $(\mathrm{n}=6)$ & \multicolumn{2}{|c|}{ differentiated - } & - & - \\
\hline 1 & \multirow{6}{*}{$\begin{array}{l}\text { II } \\
(n=6)\end{array}$} & 1.66 & 1.96 & 1.44 & 1.49 \\
\hline 2 & & 1.72 & 1.79 & 1.55 & 1.54 \\
\hline 3 & & 1.85 & 2.07 & 1.23 & 1.62 \\
\hline 4 & & 1.86 & 2.01 & 1.25 & 1.56 \\
\hline 5 & & 1.78 & 1.86 & 1.35 & 1.32 \\
\hline 6 & & 1.64 & 1.65 & 1.44 & 1.42 \\
\hline & $\begin{array}{l}\text { Average } \\
\text { (Gr- II) }\end{array}$ & $1.75 \mathrm{~mm}$ & $1.89 \mathrm{~mm}$ & $1.38 \mathrm{~mm}$ & $1.49 \mathrm{~mm}$ \\
\hline 7 & \multirow{6}{*}{$\begin{array}{l}\text { III } \\
(\mathrm{n}=6)\end{array}$} & 1.73 & 2.21 & 1.55 & 1.53 \\
\hline 8 & & 2.33 & 2.85 & 1.75 & 1.64 \\
\hline 9 & & 2.22 & 2.75 & 1.67 & 1.56 \\
\hline 10 & & 2.01 & 2.59 & 1.72 & 1.45 \\
\hline 11 & & 1.64 & 2.12 & 1.56 & 1.48 \\
\hline 12 & & 1.78 & 2.31 & 1.69 & 1.34 \\
\hline & $\begin{array}{l}\text { Average } \\
\text { (Gr-III) }\end{array}$ & $1.95 \mathrm{~mm}$ & $2.47 \mathrm{~mm}$ & $1.66 \mathrm{~mm}$ & $1.49 \mathrm{~mm}$ \\
\hline 13 & \multirow{6}{*}{$\begin{array}{l}\text { IV } \\
(n=6)\end{array}$} & 2.07 & 1.59 & 1.33 & 1.42 \\
\hline 14 & & 2.01 & 1.65 & 1.42 & 1.32 \\
\hline 15 & & 1.95 & 1.45 & 1.35 & 1.23 \\
\hline 16 & & 1.82 & 1.69 & 1.29 & 1.45 \\
\hline 17 & & 1.75 & 1.82 & 1.53 & 1.35 \\
\hline 18 & & 1.81 & 1.62 & 1.36 & 1.42 \\
\hline & $\begin{array}{l}\text { Average } \\
\text { (Gr- IV) } \\
\end{array}$ & $1.90 \mathrm{~mm}$ & $1.64 \mathrm{~mm}$ & $1.37 \mathrm{~mm}$ & $1.36 \mathrm{~mm}$ \\
\hline
\end{tabular}

There was little change in femoral head AC thickness from young to adult stages in this study which is akin to the reports of Venn (1978) and Adam et al. (1998) who opined that human femoral head cartilage had greater thickness in young tissue which in later years rapidly decreased in early years and it showed little change after maturity. 
Lothe et al. (1979) recorded the cartilage thickness in normal femoral head in humans aged from 6 to 90 years and stated that AC thickness from 6 to 25 years of age was $1.76 \pm 0.36 \mathrm{~mm}$ while that of 30 to 90 years of age was $1.84 \pm 0.43 \mathrm{~mm}$, the difference being very minimal. Taylor et al. (2011 and 2018) reported that human femoral head AC was significantly thicker than all quadruped hips. They stated AC thickness of $1.32 \pm 0.13 \mathrm{~mm}$ in bovine was more than porcine i.e., $1.22 \pm 0.05 \mathrm{~mm}$, which they felt was insignificant. However, they noticed a significant difference in average femoral head diameter (FHD) amongst human, bovine, porcine and ovine species. They concluded that FHD was largest in bovine followed by human, porcine and ovine species.

\section{CONCLUSION}

Present study showed variation in thickness of femoral head AC which reduced marginally with advancing age in various points of articular surface viz., lateral surface, at neck and at midpoint of femoral head. It was $1.89 \mathrm{~mm}, 1.38$ $\mathrm{mm}$ and $1.49 \mathrm{~mm}$ thick in Gr-II which reduced to $1.64 \mathrm{~mm}$, $1.37 \mathrm{~mm}$ and $1.36 \mathrm{~mm}$ thick in Gr-IV respectively. With advancing age the average length and width of femoral head increased fivefold from 2.83 and $2.43 \mathrm{~cm}$ in Gr-I (prenatal) to nearly 10.77 and $9.43 \mathrm{~cm}$ in Gr-IV (postnatal) specimens respectively. In specimens of groups II and III the articular surface of femoral head was shiny pink in color in fresh state whereas in specimens of Gr - IV it showed signs of discoloration such as yellowish spots nearer to fovea capitis along with few indentations around the neck. This feature establishes that with advancing age joint articular surface changes are possible due to wear and tear.

\section{ACKNOWLEDGEMENTS}

I would place on record my gratitude towards P.V. Narsimha Rao Telangana Veterinary University, Hyderabad, for providing all the necessities during my investigation to prosecute my Doctorate studies.

\section{REFERENCES}

Adam, C., Fel Ix Eckste In, Stefan M Ilz and Re Inhard Putz. 1998. The distribution of cartilage thickness within the joints of the lower limb of elderly individuals. J. Anatomy, 193: 203-214.
Armstrong, C.G. and Gardner, DL. 1977. Thickness and distribution of human femoral head articular Cartilage. Annal. Rheumatic Dis., 36: 407-412.

Baumann, A. Charles, Betina, B. Hinckel, Chantelle C. Bozynski, Jack Farr. 2019. Articular cartilage: Structure and restoration. Joint preservation of the knee. Springer, Cham, pp. 3-24.

Byrne, D.P., Kevin, J., Mulhall and Joseph F Baker. 2010. Anatomy \& Biomechanics of the Hip. The Open Sports Med. J., 4: 51-57.

Carpinisan, L. 2007. Comparative morphological aspects of the domestic pig and wild boar articular cartilage. Bulletin USAMV-CN., 64: 1-2.

Dyce, K.M., Sac W.O. and Wensing C.J.G. 2010. Text book of Veterinary Anatomy, $4^{\text {th }}$ Edition. St. Louis, Saunders/Elsevier. pp. 88 and 91.

FAO 1994. A Manual for Primary Animal Health Care Worker. Corporate Documentary Repository Chapter 3: Cattle, Sheep, Goats and Buffalo. Unit 9: How to age sheep, goats, cattle and buffalo, pp. 1-51.

Fermor, H.L.A,. S.W.D. McLure B, S.D. Taylor B, S.L. Russell B, S. Williams B, J. Fisher B and Ingham, A. 2015. Biological, biochemical and biomechanical characterization of articular cartilage from the porcine, bovine and ovine hip and knee. Bio-Medical Mat. Eng., 25: 381-395.

Friend, J.D. 1959. The comparative anatomy of the coxo femoral articulation of the Dog, Ox and Horse. Thesis: Master of science, Department of Anatomy, Kansas state University of Agriculture and applied sciences.

Getty R. 1984. "Sisson and Grossman's The Anatomy of the domestic animals". $6^{\text {th }}$ edition. W B Saunders Company, Philadelphia.

Kobrynczuk, F. 1976. Joints and Ligaments of hind limbs of the Europin Bison in its postnatal development. Acta Theriologica. 21(4): 37-100.

Konig, H.E. and Leibich, H.G. 2012. Text book and color atlas of Veterinary Anatomy of Domestic Mammals. Schattauer publisher, Stuttgart, New York, pp. 197-228.

Kurrat, H.J. and Oberlander W. 1978. The thickness of the cartilage in the hip joint. J. Anatomy, 126(1): 145-155.

Lothe Kari, M.A. Spycher and Ruttner, J.R. 1979. Human articular cartilage in relation to age: A morphometric study. Experim. Cell Biolo., 47: 22-28.

Luna, L.G. 1970. Manual of Histological staining methods of the Armed forces Institute of Pathology, $3^{\text {rd }}$ Edn, Mc Graw Hill Book Company, New York, pp. 8-163.

Meller, R., Schiborra, F., brandes, G., Knobloch, K., Tscherning, T., Hankemeier, S., Heesper, C., Schmiedl, A., Jagodzinski, M., Krettk, C. and Willbold, E. 2009. Postnatal maturation of Tendon, ruciate ligament, Meniscus and Articular Cartilage: 
A Histological Study In Sheep. Annal. Anatomy, 191: 575585 .

Nickel, R., Schummer, A., Seiferle, E., Wilkens, H., Wille, K.H. and Frewin, J. 1986. The Anatomy of the Domestic Animals. Vol. 1. The locomotor system of Domestic Mammals. Verlag Paul Parey, Berlin. 9

Seldes, R.M., Tan, V., Hunt, J., Katz, M., Winiarsky, R. and Fitzgerald Jr., RH. 2001. Anatomy, histologic features and vascularity of the adult acetabular labrum. J. Clin. Orthopaedic Related Res., 382: 232-240.

Soliman M K. 1975. Studies on the physiological chemistry of allantoic and amniotic fluids of buffaloes at various periods of pregnancy. Indian Vet. J., 52: 106-112.

Supriya, B., Chandrasekhara Rao, T.S., Jagapathi Ramayya, P., Suresh Kumar, R.V. 2014. Gross morphology of the hip articulation of buffalo calves (Bubalus bubalis). Int. J. Anatomy Res., 2(4): 645-49.
Suzuki, Y., Matsubayashi, J., Ji, X., Yamada, S., Yoneyama, A. and Imai, H. 2019. Morphogenesis of the femur at different stages of normal human development. PLoS ONE, 14(8): e0221569.

Taylor, S.D., Eleftherios Tsiridis, Eileen Ingham, Zhongmin Jin, John Fisher and Sophie Williams. 2011. Comparison of human and animal femoral head chondral properties and geometries. Proce. Insti. Mecha. Eng. Part H: J. Eng. Med., 226(1): 55-62.

Taylor, S.D., Eleftherios Tsiridis, Eileen Ingham, Zhongmin Jin, John Fisher and Sophie Williams. 2018. Assessment of femoral heads from different species for use in an in-vitro simulation. Orthopaedic Proceedings. 94B

Venn, M.F. 1978. Variation of chemical composition with age in human femoral head cartilage. Annal. Rheumatic Dis., 37: 168-174. 